\title{
Some studies on curing and drying characteristics of turmeric rhizomes
}

\author{
M. PAdMA ${ }^{1 *}$, B. SREEnivasula REDDY ${ }^{2}$ AND M. MadHAVA ${ }^{2}$ \\ ${ }^{1}$ Agricultural College, JAGTIAL (TELANGANA) INDIA \\ ${ }^{2}$ College of Agricultural Engineering, BAPATLA (A.P.) INDIA \\ Email : padma2386@gmail.com \\ *Author for Correspondence \\ Research chronicle : Received : 14.03.2016; Accepted : 28.05.2016
}

\section{SUMMARY :}

Turmeric is an important commercial spice crop grown in India and it is named as "Indian saffron". Turmeric is grown in tropical countries like India, Pakistan, Myanmar, Chile, Peru, El Salvador, Japan, China, Sri Lanka, Bangladesh, Indonesia, Taiwan, Jamaica, Thailand and West Indies. India accounts for 80 per cent of the global production of turmeric. The quality of turmeric powder depends upon the initial quality of rhizomes and on-farm processing of turmeric rhizomes which effects curcumin content, organoleptic characteristics, size and general appearance of the dried turmeric rhizomes. The on farm post harvest processing operations consists of washing, curing, drying, polishing, grading and colouring. Among all, curing, drying and polishing are the important operations of turmeric processing. Curing is a process of cooking the raw rhizomes in hot water to obtain attractive colour, characteristic aroma, destroy the viability of the fresh rhizomes and obviate the raw odour, reduces the time of drying, ensures an even distribution of colour in the rhizomes and gives a better quality product by gelatinisation of the starch (Purseglove and Brown, 1981). Method of curing turmeric varies from place to place. Drying of agricultural produce is an important factor in agricultural processing for improving the keeping qualities of the produce. Utilization of the solar energy for drying the agricultural produce is important. Since all other conventional sources of energy are in the declining trend in their availability, several researchers reported that solar energy is very useful for drying agricultural produce, particularly in India, where good sunshine is available on most of the days in a year for the following reasons, (a) it is pollution free, (b) available at no cost and (c) material drying is faster. The study was conducted to obtain fundamental data on the effect of different floor materials on open yard sun drying and Polyhouse drying. It is observed that the moisture content of turmeric fingers increases with increase in temperature of curing and curing time. At the time of 90 minutes the moisture contents were $84.41,84.48,84.80$ and 85.77 per cent (w.b.) at the curing temperatures of $60,70,80$ and $90^{\circ} \mathrm{C}$, respectively. The moisture contents increased from the initial moisture content of 79.56 per cent (w.b.). It is observed that the floor materials affected the drying time marginally under the conditions of experiments, varied considerably from one method to the other. It is concluded that polyethylene sheet followed by tarpaulin are better floor materials to reduce the drying time and for good quality of turmeric powder.

KEY WORDS : Turmeric rhizomes, Polyhouse, Open sun drying, Curing, Floor materials 